\title{
O SISTEMA TIĀNXIÀ (天下) COMO ESTRATÉGIA DO ZHŌNGGUÓ (中国) - REFLEXÕES SOBRE A TRANSIÇÃO HEGEMÔNICA MUNDIAL NO LONGO SÉCULO XXI
}

Bernardo Salgado Rodrigues ${ }^{1}$ Carlos Eduardo da Rosa Martins ${ }^{2}$

Resumo: O presente artigo visa analisar a hipótese de transição hegemônica mundial a partir do declínio relativo dos Estados Unidos e da ascensão antiimperialista da China, baseada no conceito chinês de Tiānxià (天下). Utilizando-se do método empírico-dedutivo, o objetivo principal é demonstrar que esse processo de longa duração vem se acelerando no século XXI. Considera-se como variável independente a crise da globalização neoliberal, que possibilita vislumbrar uma transfiguração sistêmica a partir de aspectos relacionados à resiliência chinesa, principalmente após a pandemia da Covid-19. Desta forma, busca-se demonstrar que a China se apresenta como alternativa concreta ao neoliberalismo financeirizado ao alocar o embrionário Estado coletivista como centro da sua estrutura de reprodução econômica.

Palavras-chave: China. Estados Unidos. Geopolítica Internacional. Transição Hegemônica. Crise da globalização neoliberal.

\section{THE TIĀNXIÀ (天下) SYSTEM AS A STRATEGY OF THE ZHŌNGGUÓ (中国) - REFLECTIONS ON THE WORLD HEGEMONIC TRANSITION IN THE LONG 21ST CENTURY}

Abstract: The present article aims to analyze the hypothesis of world hegemonic transition based on the relative decline of the United States and the anti-imperialist rise of China, centered on the Chinese concept of Tiānxià (天下). Using the empirical-deductive method, the main objective is to demonstrate that this longlasting process has been accelerating in the 21st century. Thus, the crisis of neoliberal globalization is considered as an independent variable, which makes it possible to envision a systemic transfiguration based on aspects related to Chinese resilience, especially after the Covid-19 pandemic. In this way, we seek to demonstrate that China presents itself as a concrete alternative to financialized neoliberalism by allocating the embryonic collectivist state as the center of its economic reproduction structure.

Keywords: China. United States. International Geopolitics. Hegemonic transition. Crisis of neoliberal globalization.

\section{EL SISTEMA TIĀNXIÀ (天下) COMO ESTRATEGIA DEL ZHŌNGGUÓ (中国) - REFLEXIONES SOBRE LA TRANSICIÓN HEGEMÓNICA MUNDIAL EN EL LARGO SIGLO XXI}

Resumen: Este artículo tiene como objetivo analizar la hipótesis de la transición hegemónica global basada en el declive relativo de Estados Unidos y el ascenso antiimperialista de China, a partir del concepto chino de Tiānxià (天下). Utilizando el

\footnotetext{
1 Universidade Federal do Rio de Janeiro, IRID, Rio de Janeiro, Brasil, bernardosalgado90@gmail.com, https://orcid.org/0000-0002-6439-8359

2 Universidade Federal do Rio de Janeiro, IRID, Rio de Janeiro, Brasil, cadu.m@uol.com.br, https://orcid.org/0000-0003-1333-6737
} 
método empírico-deductivo, el objetivo principal es demostrar que este proceso de larga duración se ha acelerado en el siglo XXI. La crisis de la globalización neoliberal es considerada como una variable independiente, lo que permite vislumbrar una transfiguración sistémica basada en aspectos relacionados con la resiliencia china, especialmente después de la pandemia de la Covid-19. De esta manera, buscamos demostrar que China se presenta como una alternativa concreta al neoliberalismo financiarizado al ubicar el Estado colectivista embrionario como el centro de su estructura de reproducción económica.

Palabras clave: China. Estados Unidos. Geopolítica internacional. Transición hegemónica. Crisis de la globalización neoliberal.

\section{Introdução}

Desde o início do século XXI, a China vem demonstrando uma capacidade de planejamento estatal amplamente ligada a uma flexibilidade adaptativa diante das recorrentes transformações da conjuntura global. A evidência empírica comprova que a experiência chinesa vem atravessando mudanças estruturais que somente podem ser compreendidas num horizonte estratégico de longa duração, pautada pela busca da harmonia nos planos interno - com a melhoria das condições de vida da sua população - e externo - via multipolarização do poder.

Nas relações internacionais, sua assertividade não demonstrava indícios de ruptura com a ordem global estabelecida, haja vista a retórica do "desenvolvimento pacífico" (KISSINGER, 2011: SHAMBAUGH, 2013) pautado no "Consenso de Pequim" (RAMO, 2004). Entretanto, tal panorama vem se modificando radicalmente diante do declínio relativo dos Estados Unidos - impulsionado pela crise de 2008 e pela pandemia de 2020 - e da ascensão multidimensional da China.

$\mathrm{Na}$ tentativa de compreender a atuação chinesa na ordem internacional, o Tiānxià (天下) está associado à civilização e ordem na filosofia chinesa clássica, formando a base para a visão de mundo deste povo e nação. Ele consiste na representação de um sistema que permite a garantia da ordem universal como objetivo maior da política, e cuja centralidade da estratégia do Zhōngguó (中国) estaria atravessada pelo respeito à noção de soberania dos demais países, uma vez que a harmonia é a condição ontológica para a existência e desenvolvimento das coisas (LIMA, 2018): "it is a common understanding that we all live in the same world, and have to share some kind of common understanding and tolerance of each other's ideas. It is different from the concept of empire." (SISCI, 2014, pp. 33-34) De outro modo, este é um conceito de um desenvolvimento compartilhado e antiimperialista, que forma a cosmovisão de mundo de centralidade e grandeza da 
China vis-à-vis sua interação com o restante do sistema internacional. (ECONOMY; LEVI, 2014)

Neste contexto, o presente artigo visa analisar a hipótese de transição hegemônica mundial a partir da decadência do projeto de poder dos Estados Unidos e da concepção anti-imperialista da China. Utilizando-se do método empíricodedutivo e da estrutura teórica dos ciclos hegemônicos e das ondas de Kondratiev, o objetivo principal é demonstrar que esse processo de longa duração vem se acelerando no século XXI. Assim, é considerado como variável independente a crise da globalização neoliberal, que possibilita vislumbrar uma transfiguração sistêmica a partir de aspectos relacionados à resiliência chinesa, principalmente após a pandemia da Covid-19. Desta forma, busca-se demonstrar que a China se apresenta como alternativa concreta ao neoliberalismo financeirizado ao alocar o embrionário Estado coletivista como centro da sua estrutura de reprodução econômica.

O trabalho se encontra dividido em duas seções, além dessa introdução e das considerações finais: a primeira parte visa apresentar o referencial teórico que auxilia na compreensão temática da transição hegemônica mundial, baseando-se na Teoria dos Ciclos Hegemônicos, de Immanuel Wallerstein e Giovanni Arrighi, e nas Ondas Longas de Nikolai Kondratiev. Subsequentemente, serão analisados cinco aspectos empíricos no século XXI que contribuem para a ratificação das premissas apresentadas: 1) a constatação de uma nova ordem internacional pós-ocidental e uma embrionária Nova Formação Econômico-Social na China; 2) o avanço exponencial na área de ciência, tecnologia e inovação, ditando as regras da $4^{\underline{a}}$ Revolução Industrial e da tecnologia 5G (e, futuramente, da 6G); 3) a configuração de uma estrutura geopolítica e geoeconômica sinocentrada, através de projetos como os BRICS, a Organização para Cooperação de Xangai (SCO) e o Belt and Road Initiative (BRI); 4) a tentativa de criação de uma nova arquitetura financeira mundial, lastreada pela internacionalização do renminbi e a criação da moeda digital chinesa; e 5) uma política externa mais assertiva, principalmente pelo que se pode denominar de "Fator Xi".

\section{O Sistema-mundo capitalista e a crise da globalização neoliberal a partir dos Ciclos Hegemônicos e dos Ciclos de Kondratiev}

Os ciclos sistêmicos estão intimamente relacionados à ascensão e crise de um Estado hegemônico no moderno sistema mundial e, portanto, repercutem diretamente sobre as reflexões da transição hegemônica mundial no século XXI. Historicamente, este Estado condiciona e define as regras do comércio 
internacional, a circulação de capitais, a moeda internacional, os limites entre a paz diplomática e a guerra ilimitada.

Immanuel Wallerstein (1980: 1984) foi o primeiro autor a sistematizar de forma coesa os ciclos sistêmicos, apresentando um modelo teórico de elevado caráter analítico. Ele define a hegemonia como o breve período de tempo em que uma potência expressa sua superioridade produtiva, comercial e financeira, no qual todo e qualquer hegemón no sistema-mundo, historicamente, passa da fase de liderança para a de decadência econômica, determinada pelo desenvolvimento do liberalismo global. Em outros termos, ainda que o liberalismo permita à potência dominante aproveitar as vantagens de sua liderança e elevar sua capacidade de persuasão, também deteriora esse poder na medida em que a circulação dos fatores de produção implica a difusão de know-how tecnológico, estimulando àqueles que estão próximos à fronteira tecnológica ao desenvolvimento de produtos simulacros sem arcarem com os custos iniciais da inovação.

Essas superioridades são sucessivas, mas se interpõem no tempo. A perda
de vantagem parece seguir a mesma ordem (desde a produtiva até a
comercial e desta à financeira) e ser boa parte sucessiva. Daqui se
depreende que provavelmente somente há um breve período de tempo em
que uma determinada potência do centro pode manifestar simultaneamente
sua superioridade produtiva, comercial e financeira sobre todas as outras
potências do centro. É esse efêmero período que chamamos de hegemonia.
(WALLERSTEIN, 1984, pp. $51-52$.)

Outro importante autor dessa corrente teórica foi Giovanni Arrighi (1996: 2008), propondo uma reinterpretação do conceito de hegemonia relacionada à capacidade de liderar a superestrutura política e ideológica do moderno sistema mundial. Ainda que com diferenças epistemológicas com Wallerstein, o autor também realiza uma proposição de ciclos sistêmicos, cuja constatação da hegemonia possui uma dimensão adicional ligada à capacidade de um determinado Estado estabelecer a institucionalidade da economia-mundo. Desta forma, estes ciclos se dividem em três etapas: expansão hegemônica, crise hegemônica e caos sistêmico.

A expansão hegemônica corresponderia a uma fase $A$, quando um determinado Estado hegemônico concentra o poder produtivo, comercial, financeiro, militar e ideológico necessário para perpetrar um novo direcionamento ao sistema mundial. Para Martins (2011), esta fase ascendente da hegemonia estadunidense fundou-se: a) na liderança tecnológica e financeira do paradigma tecnológico eletromecânico; b) na articulação da economia mundial por investimentos diretos dirigidos ao mercado interno dos países receptores; c) numa maior intervenção do 
Estado na economia (ampliando gastos, principalmente no setor militar, e direcionando-os para a expansão da produção e do comércio); d) na construção de organismos intergovernamentais a partir da ONU, que exerceram tarefas políticas atreladas à consecução de uma nova institucionalidade global; e, e) na ideologia de integração hemisférica em torno do mundo livre e ocidental.

A fase B de crise hegemônica caracterizar-se-ia por uma expansão financeira em detrimento da produtiva, uma vez que o Estado hegemônico tem deteriorados seus poderes produtivo e comercial, e responde a esse desgaste dilatando sua capacidade de acumulação financeira independente da expansão de sua base material. Em outros termos, há uma relação inversamente proporcional e contraditória entre a expansão dos poderes financeiro e ideológico, e a contração dos poderes produtivo e comercial. Adicionalmente, a crise de longa duração da hegemonia estadunidense vem se intensificando por meio do declínio do sistema de inovação estadunidense diante do paradigma tecnológico oriundo de outros Estados nacionais, em particular a China. Além disso, também apresenta importantes elementos socioculturais - constantes movimentos sociais antissistêmicos - e institucionais - desmonte relativo da institucionalidade originada no Pós-Segunda Guerra. Ainda que a hegemonia estadunidense esteja incomparavelmente pautada no poder do dinheiro e das armas (FIORI, 2008), fatores-chave reforçam um quadro cada vez mais efetivo de crise hegemônica, inclusive reduzindo-se o horizonte temporal da longa duração na transição hegemônica.

A terceira etapa consiste no denominado caos sistêmico, um período anárquico que se inicia quando os poderes financeiro e ideológico não possuem mais a capacidade de sustentação ao estabelecer o interesse geral na economiamundo. Esta fase é marcada por guerras e pela competição interestatal entre dois grandes blocos históricos rivais, que disputam o protagonismo global em novos marcos institucionais, que seriam capazes de reorganizar o consentimento no sistema mundial. Basicamente, esse é o panorama atual das relações internacionais, com centralidade no processo de ascensão da China, que vem tensionando os limites da hegemonia estadunidense em múltiplas frentes, evidenciando intensos desafios econômicos, políticos e militares.

No final da década de 2010, sob o governo Trump, foram intensificados a desregulamentação financeira, uma política fiscal regressiva, o aumento dos gastos militares, o abandono do liberalismo político, uma política externa unilateralista e protecionista. Todos esses fatores ratificam a fase $B$ do ciclo sistêmico da 
hegemonia dos EUA, acelerando a trajetória de seu declínio, ao invés de revertê-la, criando espaço para seus rivais se afirmarem no tabuleiro geopolítico global.

Outro aporte teórico que ratifica essa tendência são os ciclos de Kondratiev (1992), que caracteriza o desenvolvimento do capitalismo histórico e auxilia na compreensão sistemática da crise da globalização neoliberal. Desde o final do século XVIII, o autor sinaliza para os ciclos longos de aproximadamente quarentena e oito a sessenta anos, divididos em fases A (de crescimento econômico) e B (de recessão), com uma margem de oscilação de cinco a sete anos. Tanto os ciclos econômicos quanto as fases propostas pelo autor possuem uma forte dependência dos fenômenos tecnológicos, geopolíticos e superestruturais.

Estes ciclos possuem oscilações marcadas pela acumulação ilimitada em: a) fases expansivas, que se manifestam em trajetórias tecnológicas que desenvolvem inovações primárias, secundárias e terciárias em torno de um paradigma tecnológico; b) fases recessivas, com a convergência das crises de acumulação, desproporção, realização e da tendência decrescente da taxa de lucro; e c) de superação da fase recessiva, que exige uma reformulação institucional e organizacional que implica uma simbiose de originalidades, tais como padrões empresariais, formas de internacionalização do capital e de centralização financeira, regime de regulação do trabalho, força de trabalho, intervenção estatal e liderança internacional.

Para Nicolai Kondratiev (1992), as fases expansivas correspondem aos períodos de maior convulsão social e guerras, uma vez que representam a etapa em que as forças da renovação colidem diretamente com as da obsolescência, e acentuam a competição por mercados e matérias-primas. Adicionalmente, a crise de longo prazo do Kondratiev significa uma convergência das crises de acumulação e de queda da taxa de lucro, uma vez que o ciclo econômico encontra limites para a sua expansão indefinida.

Uma vez desencadeado, o ciclo econômico encontra limites para a sua expansão indefinida, que se tornam um obstáculo efetivo após 25-30 anos, quando a curva de investimento se elevaria acima da curva de acumulação. Isso se explica pelo aumento da obsolescência dos meios de produção e pelo crescimento da demanda por capital para investimento que a competição intercapitalista impulsiona. O resultado seria a inflexão negativa na curva de geração de excedentes e uma elevação das taxas de juros que encareceria o investimento e derrubaria o lucro, estabelecendo uma onda descendentedepressiva. A onda descendente, por sua vez, prepararia as condições para num prazo semelhante criarem-se as bases do estabelecimento de outro ciclo longo. (MARTINS, 2011, p. 87) 
Em suma, no que se refere à transição hegemônica no século XXI, Martins (2011) propõe outra periodização dos ciclos sistêmicos como método prospectivo do encerramento do atual ciclo estadunidense. Baseando-se na medição dos ciclos de Arrighi (1996), a postulação do seu término - excluindo-se o período de caos sistêmico - estaria entre 2015 e 2020. Acrescentando-se o esgotamento da fase A do ciclo de Kondratiev pós-1994, que se encerraria em 2020, ratificar-se-ia que a crise da Covid-19 é, provavelmente, o ponto de inflexão para as próximas décadas, que ensejará o caminho para um período de caos sistêmico.

Desde meados da década de 2010, o processo de globalização neoliberal, iniciado em 1979 e impulsionado politicamente a partir da década de 1990, demonstra sinais de esgotamento. Os números decrescentes do crescimento global indicam que não é mais possível mitigar o forte aumento nos níveis acumulados de desigualdade ao conter ou amenizar a pobreza. Isto significou a decadência acelerada de suas forças motrizes, visualizadas no declínio hegemônico do liberalismo político, no aumento das tensões e conflitos militares armados no sistema mundial e no relativo e embrionário desgaste do padrão monetário dominante.

O possível giro do sistema mundial teria drásticas implicações transformadoras: inverteria os 520 anos de protagonismo europeu ou anglo-saxão, marcados pela forte presença do imperialismo, em favor de um novo padrão mais horizontal e pacifista reinventado sob as bases do Zhōngguó (中国) e do sistema Tiānxià (天下); daria uma presença inédita ao Estado no estabelecimento do padrão de acumulação; estabeleceria pressões sociais inéditas sobre o centro do sistema, em razão da presença de $20 \%$ da população mundial em seu âmbito; e colocaria um partido comunista em situação de protagonismo, em confrontação com o padrão liberal que marcou o moderno sistema mundial.

Desta forma, "a época em que vivemos combina o movimento de descenso de um ciclo sistêmico, o estadunidense, e a emergência do novo Kondratiev." (MARTINS, 2011, p. 100) Logo, uma das hipóteses é que este caos sistêmico tende a colocar em xeque não somente o centro hegemônico do sistema mundial moderno, mas concomitantemente suas próprias fundações e fundamentos, possibilitando a sinalização de um período de transição para um novo sistema sinocêntrico. Na continuação, serão delineados alguns elementos que comprovariam esta proposição, baseados nas estratégias chinesas ao longo do século XXI, e que 
tendem a intensificar e tencionar cada vez mais a luta pelos blocos hegemônicos de poder no sistema internacional.

\section{1) As cinco estratégias do Zhōngguó (中国) no longo século XXI}

a) Ordem internacional pós-ocidental e Nova Formação Econômico-Social

O século XXI vem apresentando uma nova geometria de poder no sistema internacional. A própria mutabilidade empírico-materialista da China é uma constante visualizada nas inúmeras terminologias qualitativas de seu modelo: reforma com "características chinesas" (ARRIGHI, 2008: KISSINGER, 2011), "economia de mercado não capitalista" (ARRIGHI, 2008), "capitalismo confucionista" (ENCINA, 2009), "capitalismo do Rio Amarelo" (LEONARD, 2008), "desenvolvimento pacífico" (KISSINGER, 2011: VADELL, 2011: SHAMBAUGH, 2013), "mundo harmonioso" (KISSINGER, 2011: LEONARD, 2008: SHAMBAUGH, 2013), "ascensão na cooperação" (NIU, 2013), "Consenso de Pequim" (RAMO, 2004) ou "Asiático" (VADELL; RAMOS; NEVES, 2016), dentre outros.

Nestes termos, o próprio 13ํㅗㄱono Quinquenal (2016-2020) é decisivo para a conformação de uma identidade, para a conclusão da construção de uma sociedade moderadamente próspera e, nos termos do presente artigo, para criar as bases para a transição hegemônica. Tal fato é possível uma vez que o documento visa um direcionamento para se adaptar proativamente a um desenvolvimento econômico inovador (principal força motriz), coordenado (qualidade integral, sustentada e saudável), verde (condição necessária para garantir um crescimento duradouro), aberto (vital para a prosperidade da China) e compartilhado (essência do socialismo ao estilo chinês), no qual outras regiões do mundo possuem papel fundamental.

Segundo Stuenkel (2018), o século XXI vem se configurando como um mundo pós-ocidental, pós-unipolar e de multipolarização (e democratização) da ordem global futura. Ainda que o autor afirme que existe a criação de uma ordem paralela complementar e não confrontativa das potências emergentes, é necessário que os embriões institucionais da nova ordem sejam desenvolvidos na antiga, reformando as próprias estruturas da governança global ao realizar um salto qualitativo a partir do conceito de jìng zhong yǒu dòng (静中有动), um pensamento taoísta que significa "ação dentro da não-ação", ou "na paralisação há movimento", um princípio de aguardar o timing apropriado para só então completar um objetivo último em alguma extensão pretendida. (KAVALSKI, 2012) 
Adicionalmente, uma vez que os conceitos das relações internacionais são amplamente ocidentocêntricos, esta visão "leva a subestimar não só o papel que atores não ocidentais desempenharam no passado e desempenham na política internacional contemporânea, mas também o papel construtivo que provavelmente desempenharão no futuro." (STUENKEL, 2018, p. 210) Uma visão crítica similar e complementar é visualizada por Napoleoni (2014), atestando tanto a falência do capitalismo e da democracia ocidental quanto a força motriz chinesa no que tange as mudanças econômicas e financeiras que ocasionarão um impacto na vida das pessoas e nas relações internacionais.

Concomitantemente, a autora afirma que há em curso um comprometimento chinês com a produção de um novo modelo de sociedade, um híbrido políticoeconômico entre o capitalismo e o comunismo, um viveiro de transformações socioeconômicas que assegura mais progresso e bem-estar do que os outros sistemas. Portanto, há a necessidade imperativa de compreender as mudanças em curso ao "reinterpretar a teoria marxista no contexto de Pequim. Até aqui, o modelo chinês parece ser uma lente adequada à análise da decadência da sociedade ocidental e do declínio do nosso capitalismo." (NAPOLEONI, 2014, p. 23)

Numa visão marxiana, o mercado não deixa de existir no socialismo; ele estaria submetido ao controle público, direcionado ao bem social. Na China, este é um processo que não pode ser compreendido como uma pura manifestação da oposição entre Estado e mercado. Seguindo esta mesma linha de raciocínio, Braudel distingue os conceitos de "economia de mercado" e de "capitalismo", defendendo a tese de que o capitalismo é o "antimercado", uma vez que "o mercado é o lugar das trocas e dos ganhos 'normais' e o capitalismo, o lugar da acumulação dos 'grandes lucros' e dos 'grandes predadores'." (BRAUDEL apud FIORI, 2007, pp.14-15)

No que tange à formulação teórico-epistemológica da uma nova formação econômico-social na China, os trabalhos de Gabriele (2020) e Jabbour (2019) são extremamente elucidativos. Neste contexto, Gabriele (2020) pretende identificar um núcleo mínimo comum compartilhado por formas variadas de empresas, que povoaram a paisagem do complexo processo da China na era do socialismo de mercado, e que ainda constituem a espinha dorsal da sua economia. Assim, o conceito de Non-Capitalist Market Oriented Enterprises (NCMOEs) é mais amplo do que o tradicionalmente associado às empresas estatais e cooperativas, cujo núcleo é constituído por empresas estatais (State-Owned Enterprises - SOEs) centrais 
controladas pela State-owned Assets Supervision and Administration Commission of the State Council (SASAC) ${ }^{3}$, que não são, prioritariamente, orientadas para 0 mercado. Assim, o Estado avança aonde o setor privado recua, principalmente em contextos de crise sistêmica, como em 2008, e, mais recentemente, em 2020. Inclusive, esta nova formação econômico-social realiza um poderoso impulso de investimentos expansionistas anticíclicos, que necessariamente orbitam em torno de empresas industriais controladas pelo Estado que, direta e indiretamente num contexto de longo prazo, planeja e projeta o comando, a criação e a moldagem dos mercados.

Para Jabbour (2019), a criação de uma nova formação econômico-social é um processo histórico de inovações institucionais, capacidades estatais e saltos qualitativos no seio do setor estatal na economia chinesa, fundamentais ao surgimento de novas e superiores formas de planificação econômica e estágio superior de desenvolvimento, denominado pelo autor de "Nova Economia do Projetamento". Esta é visualizada como uma etapa superior do socialismo de mercado chinês e uma síntese de uma série de capacidades estatais construídas ao longo do tempo. Ao se pautar num projeto que intenta modificar a estrutura produtiva e organizacional, o projetamento visa maximizar a racionalização do processo de produção ao condicionar a utilidade como desenvolvimento do bem comum. Em outros termos, é um salto qualitativo em relação à economia guiada pelo mercado capitalista, configurando-se como a antítese do neoliberalismo e da financeirização, inclusive ao direcionar a economia para o setor produtivo de inovações endógenas rumo à fronteira tecnológica.

Nesta visão, o Estado chinês é a força política que possui o controle dos fatores estratégicos e dos setores produtivos em indústrias-chave, possibilitando uma flexibilidade adaptativa e eficiência célere numa avançada engenharia políticosocial. Segundo Jabbour e Paula (2018), os ciclos de inovação institucional possibilitam uma reorganização de atividades entre os setores estatal e privado da economia. Desde 1978, essas inovações vêm levando a um crescimento quantitativo do setor privado, enquanto que o Estado vem elevando seu papel de forma qualitativa via controle político do país e constituindo-se como participante ativo nos

\footnotetext{
${ }^{3}$ A Comissão de Supervisão e Administração de Ativos Estatais do Conselho de Estado (State-owned Assets Supervision and Administration Commission of the State Council - SASAC) é um comitê especial da República Popular da China, diretamente subordinada ao Conselho de Estado, responsável pela gestão de SOEs, incluindo a nomeação de altos executivos e aprovação de quaisquer fusões ou vendas de ações ou ativos, bem como a elaboração de leis relacionadas a empresas estatais.
} 
módulos de acumulação de capital, principalmente através da grande manufatura, do sistema financeiro, da política de juros, do câmbio, do fluxo externo de capitais, da coordenação e socialização do investimento. Em outros termos, ainda que paradoxalmente o Estado detenha somente $30 \%$ do controle sobre os fluxos de renda do país (PIKETTY; YANG; ZUCMAN, 2017: NAUGHTON, 2017: NOGUEIRA; GUIMARÃES; BRAGA, 2019), ele possui uma capacidade maior de intervenção sobre a realidade econômica e social do que no nas décadas de 1980 e 1990.

Jabbour (2019) caracteriza cinco pontos fundamentais que auxiliam na consolidação desta nova formação econômico-social: 1) um novo poder político, fundado nos marcos da Revolução de 1949, capaz de gerenciar as mudanças institucionais necessárias ao enfrentamento das contradições inerentes ao processo de desenvolvimento; 2) um profundo e capilarizado sistema financeiro público de longo prazo; 3) a transformação do comércio exterior em um "bem público planificado e de Estado" (JABBOUR; DANTAS, 2017, p. 794); 4) a formação e o fortalecimento de 97 grandes conglomerados empresariais estatais (GCEE), responsáveis pela geração de efeitos de encadeamento a todo o conjunto da economia nacional chinesa; e 5) o surgimento, em 2003, da SASAC, instituição responsável pelo gerenciamento dos ativos e interesses estatais nos GCEE.

Em suma, a China expõe ao sistema internacional uma nova formação econômico-social, cuja "socialisticidade" vem se elevando na medida em que avança o século XXI. Pode-se concluir que a China não realiza a distinção ocidentocêntrica entre capitalismo e socialismo, realizando uma harmonia entre extremos, cujo consenso entre os diferentes seria a base do modelo chinês na atualidade, de matiz claramente confuciana. A partir do lema "crossing the river by feeling for stones" (摸着石头过河), visualiza-se que a China é um processo de transformação permanente, uma economia híbrida que planeja seus desafios e propostas de longo prazo para o mundo. Em outros termos, ainda que o país asiático habite um sistema internacional capitalista, gradativamente apresenta características não capitalistas. É um modelo socialista de construção histórica de longa duração, de contradições temporais, de unidade entre contrários; um paradoxo do velho com o novo, um Estado coletivista embrionário em sua trajetória no sistema internacional, mas que se destaca amplamente nas ponderações sobre a transição hegemônica. 
b) Paradigmas científicos, tecnológicos e inovativos

O desenvolvimento do sistema nacional de inovação é a maior prioridade da China no início do século XXI, progredindo num curto espaço de tempo em todos os aspectos da denominada $4^{\mathrm{a}}$ Revolução Industrial ${ }^{4}$. O componente central deste sistema de ciência, tecnologia e inovação (C,T\&l) chinês é constituído por organizações totalmente públicas e não voltadas para o mercado, fazendo com que o poderoso papel intervencionista deste Estado utilize ferramentas pesadas de planejamento com instrumentos de política visando o progresso técnico, a endogenização e a independência. Em outros termos, o objetivo fundamental da China é realizar um salto qualitativo decisivo em seu sistema de inovação nacional, reduzindo drasticamente sua dependência tecnológica estrangeira e desenvolvendo uma capacidade sistêmica para gerar inovações endógenas de poder tecnológico de primeiro nível. (GABRIELE, 2020)

É explícito que a China está determinada em alcançar a fronteira tecnológica e a produção da técnica mais avançada no mundo. Esse esforço chinês é originado na primeira década do presente século, ocasionado principalmente a partir da exaustão do crescimento com tecnologia importada e consequente declínio da complementaridade tecnológica com os EUA e 0 Japão. ${ }^{5}$ Este processo se intensifica na década de 2010, em que o rumo da conformação de um estágio mais avançado pode ser visualizado no megaprojeto "Made in China 2025", um plano estratégico emitido pelo primeiro-ministro chinês Li Keqiang, em maio de 2015, servindo como um guia para a estratégia industrial chinesa. Ele propõe um modelo de desenvolvimento independente e aberto à cooperação global com princípios voltados à inovação, qualidade dos produtos, processos e estruturas, economia verde e aperfeiçoamento do capital humano. Deste modo, as metas estratégicas consistem em transformar o gigante asiático numa grande potência industrial de alto

\footnotetext{
${ }^{4}$ A Quarta Revolução Industrial (4⿳亠丷厂 ${ }^{-}$R.I.) é definida através da transição direcionada a novos sistemas que foram construídos sobre a infraestrutura da revolução digital: inteligência artificial (IA), robótica, internet das coisas (IoT), veículos autônomos, impressão em 3D, nanotecnologia, biotecnologia, ciência dos materiais, armazenamento de energia e computação quântica. Segundo Schwab (2016), a $4^{\text {a }}$ R.I. possui como características principais a velocidade (evolui num ritmo exponencial e não linear), a amplitude e profundidade (revolução digital como base que combina várias tecnologias) e o impacto sistêmico (envolve a transformação de sistemas inteiros entre países, empresas, indústrias e toda sociedade). Em outros termos, a Quarta Revolução Industrial é a fusão dessas tecnologias e a interação entre os domínios físicos, digitais e biológicos.

${ }^{5}$ Desde o $11^{\circ}$ Plano Quinquenal (2006-2010) a prioridade são investimentos em tecnologias centrais como semicondutores e softwares, e, no $13^{\circ}$ plano Quinquenal (2016-2020), a inovação se institucionaliza no planejamento estratégico. Ainda, desde 2010, visualiza-se uma corrida em torno do domínio das técnicas de Inteligência Artificial, em que algumas empresas em conjunto com a Huawei possuem projetos para a plataforma $6 \mathrm{G}$.
} 
valor agregado em dez anos: "we will strive to transform China into the global manufacturing leader before the centennial of the founding of New China, which will lay the foundation for the realization of the Chinese dream to rejuvenate the Chinese nation." (CHINA, 2015, p. 1)

Atualmente a China dispõe do maior Big Data ${ }^{6}$ do mundo, sintetizado no acrônimo BAT 7: a Baidu, empresa multinacional chinesa de tecnologia especializada em serviços e produtos relacionados à Internet e inteligência artificial, realiza o registro das buscas em sua plataforma; a Alibaba, empresa multinacional de tecnologia especializada em e-commerce, varejo, Internet e tecnologia, compila e centraliza as compras e vendas; e a Tencent, um conglomerado de tecnologia multinacional que comercializa globalmente serviços e produtos relacionados à Internet, como entretenimento, inteligência artificial e outras tecnologias, cataloga o que se faz, paga e joga. Desta forma, o BAT se configura como um dispositivo de automatização de governança colossal.

Suplementarmente, agrega-se a esse caleidoscópio tecnológico as gigantes chinesas de telecomunicações Huawei, ZTE e Xiaomi. A primeira dessa lista lidera a tecnologia $5 \mathrm{G}$, a quinta geração das redes sem fio, que oferece banda larga onipresente e de baixo custo, com baixa latência, conectividade em alta velocidade, e melhora a experiência do usuário na smart home (casa inteligente), no vídeo HD de $4 \mathrm{~K} / 8 \mathrm{~K}$ e em VR/AR (Realidade virtual/Realidade aumentada). Segundo Lin (2020), esta nova geração não constitui apenas uma tecnologia sem fio, mas um

6 Big Data consiste num conjuntos gigantesco de dados que podem ser analisados computacionalmente para revelar padrões, tendências e associações, especialmente em relação ao comportamento e interações humanas.

7 "The first and most important difference is the presence of channel-straddling media powerhouses. These include, most notably, Baidu, Alibaba, and Tencent, which together are known by the acronym BAT. To put this in a Western context, imagine if Amazon, Bank of America, Google, Facebook, Activision Blizzard, CNN, and ESPN were all owned by one company. That's essentially how the big conglomerates work in China, with the BAT companies controlling most of the digital content across industries. For example, Tencent owns the world's largest gaming platform, a wide array of news agencies, the dominant social media platforms in China (Weixin and WeChat), financial services platforms (WeChat Pay and QQ Red Envelope Mobile Pay), retail investments (Tencent is the secondbiggest shareholder in JD.com, one of China's largest online retailers), Tencent Video (the largest streaming service in China, with over 43 million subscribers), and Tencent Sports (China's number one online sports-media platform). Almost all media activity in China is consolidated on mobile devices, with consumers spending, on average, seven hours a day looking at their phones-approximately twice as much time as Americans spend. Remarkably, $55 \%$ of all online time spent by Chinese consumers is within the Tencent ecosystem of companies, according to data from Kleiner Perkins. The regulatory environment in the West prohibits such concentration, and as a result, Western marketers have been trained to use highly fragmented, channel-centric strategies to reach consumers. Marketing theories developed in this kind of media landscape don't easily translate to China-and perhaps more important, they may blind Western companies to the opportunities that exist when data is aggregated within a single, channel-straddling company." (WHITLER, 2019) 
ecossistema organizado no qual tecnologias e ferramentas variadas podem desempenhar todo o seu potencial.

Ainda de acordo com Lin (2020), a utilização combinada do 5G com a Inteligência Artificial $(\mathrm{IA})^{8}$ e a Internet das Coisas $(\mathrm{IOT})^{9}$, ou Inteligência Artificial das Coisas (AloT, na sigla em inglês), promete revolucionar o cotidiano das pessoas em áreas como finanças, manufatura, educação, transportes, assistência médica, dentre outros (XIN, 2020). Além disso, compõe a estratégia-chave de empresas como Huawei e Xiaomi para os próximos anos, ao compatibilizar a futura supernetwork " $5 \mathrm{G}+|\mathrm{A}+| \mathrm{O} T$ ". Neste sentido, o governo chinês tem dado importância crescente à pesquisa e ao desenvolvimento dessas tecnologias recentemente, inclusive tendo criado seis zonas piloto para desenvolvimento inovador de IA, em Pequim, Xangai, Tianjin, Shenzen, Hangzhou e Hefei. Esses novos paradigmas colocam as capacidades produtivas num patamar mais elevado e que, somado à computação quântica $^{10}$, computação evolucionária ${ }^{11}$, algoritmos evolutivo ${ }^{12}$ e deep learning ${ }^{13}$, ensejam à economia chinesa um padrão de acumulação baseado nas inovações e tecnologias das principais cadeias globais de valor, tais como energia renovável, trens de alta velocidade, o próprio $5 \mathrm{G}$ e, futuramente, o 6G. ${ }^{14}$

\footnotetext{
${ }^{8}$ A Inteligência Artificial (IA) refere-se à simulação da inteligência humana em máquinas que são programadas para pensar como humanos e imitar suas ações. $O$ termo também pode ser aplicado a qualquer máquina que exiba características associadas à mente humana, como aprendizado e resolução de problemas. É uma tecnologia que possibilita encontrar padrões muito sutis em enorme quantidade de dados.

9 Internet das coisas (Internet of Things, loT) é um sistema de dispositivos de computação, mecânicos e digitais interrelacionados, fornecido com identificadores exclusivos e capacidade de transferir dados em uma rede sem a necessidade de interação humano-humano ou humano-computador.

${ }^{10} \mathrm{~A}$ computação quântica é o uso de fenômenos quânticos, como superposição e emaranhamento quântico, com a finalidade de realizar cálculos. Os computadores que realizam cálculos quânticos são conhecidos como computadores quânticos.

${ }^{11}$ A computação evolucionária (CE) é uma família de algoritmos para otimização global inspirada na evolução biológica e no subcampo da inteligência artificial e computação suave que estuda esses algoritmos. Ela tem recebido atenção significativa na China nas últimas duas décadas. Gong et al (2016) realizam uma visão geral do estado atual desse campo em rápido crescimento na China, com fundamentos teóricos, otimização, mineração de dados e aplicações do mundo real.

${ }^{12} \mathrm{Na}$ inteligência artificial (IA), um algoritmo evolutivo é um subconjunto da computação evolutiva, um algoritmo de otimização metaheurística. Ele usa mecanismos inspirados pela evolução biológica, como reprodução, mutação, recombinação e seleção. São normalmente usados para fornecer soluções adequadas e aproximadas para problemas que não podem ser resolvidos facilmente com outras técnicas.

13 Deep learning é uma das bases da inteligência artificial (IA), um tipo de machine learning que treina computadores para realizar tarefas como seres humanos, o que inclui reconhecimento de fala, identificação de imagem e previsões. Em vez de organizar os dados para serem executados através de equações predefinidas, o deep learning configura parâmetros básicos sobre os dados e treina 0 computador para aprender sozinho através do reconhecimento de padrões em várias camadas de processamento.
}

14 No final de 2019, o ministério chinês da Ciência e Tecnologia anunciou o início do processo de estudos para desenvolvimento de rede 6G, que deverá ser uma realidade comercial em meados de 2030. A empresa chinesa Huawei, líder na tecnologia 5G no mundo, é uma das instituições que 
É importante ressaltar que existe uma economia política dentro das cadeias globais de valor, em que a disputa política das empresas se relaciona com os interesses dos Estados nacionais. A geopolítica cibernética é uma luta pelo controle e fluxo da informação e redes de tecnologias disruptivas fundamentais. ${ }^{15}$ Seja na tentativa estadunidense de inviabilizar o fornecimento de microchips da taiwanesa TSMC e da sul-coreana Samsung para a Huawei; na proibição do aplicativo chinês Tiktok nos Estados Unidos, sob a prerrogativa de segurança nacional; ou na dependência na produção de microchips e semicondutores, que, apesar dos avanços no seu desenvolvimento e modernização, prescinde dos insumos estadunidenses, principalmente para atender às suas necessidades de consumo e à fronteira tecnológica em design e fabricação (MAJEROWICZ; MEDEIROS, 2018), a guerra tecnológica sino-americana possui um caráter amplamente paradoxal e dicotômico: por um lado, pode dificultar o progresso do $5 \mathrm{G}$ e de tecnologias chinesas, principalmente na modernização das forças armadas e em infraestruturas críticas; e, por outro lado, as sanções estadunidenses podem fazer com que a China potencialize o seu catch up, fortalecendo seu poder de barganha baseado em seu mercado consumidor interno de circuitos integrados e viabilizando as capacidades de design e fabricação de microchips e semicondutores na produção endógena.

Ainda que haja distintos gaps na capacidade tecnológica e inovativa da China ${ }^{16}$, nenhum outro país do mundo tem a capacidade de avançar

realizam a pesquisa desta inovação. Com a perspectiva de atingir velocidades de 1 TB (terabyte) por segundo, aproximadamente 8 mil vezes mais rápidas que as redes de quinta geração, o 6G ainda possuiria vantagens comparativas de largura de banda, baixa latência e conexões amplas em relação ao $5 \mathrm{G}$, revolucionando a estrutura de toda a rede cabeada e sem fio.

15 A China vem salvaguardando estrategicamente suas indústrias domésticas para criar empregos e valor agregado, ao invés de tornar o mercado chinês um agente passivo para a lucratividade dos capitais ocidentais. Os ataques oriundos dos Estados Unidos à política econômica chinesa se concentram em subsídios e empresas estatais, restrições ao capital estrangeiro e transferência de propriedade intelectual. Todas essas políticas são os principais pontos de fomento da indústria nacional chinesa e evitaram a dependência dos capitais ocidentais. A guerra comercial em curso vem buscando abrir o gigantesco mercado interno da China principalmente para as firmas produtivas e financeiras dos Estados Unidos. Este é o ponto crucial das constantes agressões econômicas estadunidenses à China.

16 "China e Estados Unidos são dois líderes globais em IA, mas a China está bem atrás em capacidade tecnológica e estrutura industrial. Ela precisa acertar o passo em pesquisa fundamental e no número de pesquisadores de IA, de empresas e de teses publicadas - e sua defasagem nos dois primeiros aspectos é evidente na comparação com os EUA. O investimento feito em 2017 pela Fundação Nacional da Ciência Natural da China foi de apenas 14\% em comparação com o realizado pela Fundação Nacional de Ciências dos EUA. No mesmo ano, o número de pesquisadores de IA na China correspondia a $27 \%$ do seu número nos EUA. Em janeiro de 2019, o número de companhias de IA da China e de teses publicadas era de $55 \%$ e $95 \%$, em relação ao número dos EUA. Embora a distância em relação aos EUA seja pequena no volume de teses publicadas e de solicitação de patentes, a qualidade não está no mesmo nível - o índice chinês de FWCI (Field Weighted Citation Impact ou Impacto da Citação Medido no Setor) é metade do americano. Embora seja difícil mensurar a qualidade das patentes, a proporção delas para hardware fundamental e o algoritmo de todas as 
exponencialmente seu processo de acumulação e desenvolvimento tecnológico. A China é o primeiro país no sistema internacional de acordo com o nível absoluto de número de pessoal em P\&D e de número de patentes; classifica-se em segundo lugar de acordo com o critério holístico de avaliação de seu potencial de inovação geral ${ }^{17}$; vem diminuindo rapidamente a diferença em investimento em $P \& D$, número de pesquisadores, gastos em loT, e novas empresas globais. A China é um ator global importante para o desenvolvimento em C,T\&I, que poderá oferecer uma grande contribuição ao progresso e crescimento econômico mundial.

c) Estrutura geopolítica e geoeconômica sinocentrada

Esta seção busca realizar um apanhado de características no âmbito geopolítico e geoeconômico que justificam as reflexões sobre uma transição hegemônica de longa duração no sistema internacional. Primeiramente, por geopolítica, compreende-se como um método de estudo dinâmico da influência de fatores geográficos no desenvolvimento dos Estados com a finalidade de orientar suas políticas internas e externas. Ou seja, como método que estuda a política derivada de aspectos geográficos, "é uma ferramenta de análise de política externa que busca compreender, explicar e prever o comportamento político internacional, principalmente em termos de variáveis espaciais." (RODRIGUES, 2020, p. 24)

O século XXI vem se configurando como um caleidoscópio geopolítico mundial tendo a China como protagonista, seja através de instituições mais tradicionais, como a Associação de Nações do Sudeste Asiático (ASEAN) e a Cooperação Econômica da Ásia e do Pacífico (APEC), ou, mais recentemente, com o Fórum de Cooperação China-África (FOCAC) e o Fórum China-CELAC. Adicionalmente, ratifica-se que os mais importantes arcabouços geopolíticos chineses no século XXI correspondem à conformação dos BRICS e da Organização para Cooperação de Xangai (OCX, ou SCO na sigla em inglês)

O grupo de países denominado BRICS (Brasil, Rússia, Índia, China e África do Sul) é uma modalidade de parceria entre países emergentes, visando constituir um mundo pós-ocidental e multipolar. (STUENKEL, 2017) Em outros termos, o

patentes chinesas são pequenos, e a adoção de patentes chinesas no exterior é limitada." (XIN, 2020, p.31)

17 Neste tocante, é importante ressaltar que a China alcançou essa conquista estando situada num estágio em que ainda se encontra defasada em relação aos líderes tecnológicos tradicionais, tanto em termos de desempenho educacional per capita, tecnológico e de pesquisa, assim como em termos de renda per capita. 
BRICS não pode ser interpretado sem considerar o papel de liderança da China no estabelecimento de novas instituições globais, que implicam em mudanças na hegemonia global. (VADELL, 2019) Em 2014, foram criados o Novo Banco de Desenvolvimento (NBD) - uma instituição voltada ao financiamento da infraestrutura e do desenvolvimento sustentável nos países membros e emergentes, sendo uma alternativa complementar (e distinta) ao Banco Mundial e ao FMI, uma vez que consiste numa cooperação financeira institucionalizada que busca romper com 0 modelo doador-recebedor tradicional -, e o Arranjo Contingente de Reservas (ACR) - um fundo de reservas mantidas pelos bancos centrais como instrumentos de precaução, que poderão ser utilizados para evitar os efeitos negativos de uma crise financeira ou no balanço de pagamentos dos países participantes.

Com o NBD e o ACR, os BRICS destacam a necessidade de maiores investimentos, especialmente nos países em desenvolvimento, diante dos recursos insuficientes das instituições existentes. "Especificamente para a China, tal arranjo institucional pode aumentar sua capacidade de negociação com as potências vigentes, aprofundar a cooperação econômica entre países emergentes, manter a paz e estabilidade nas regiões dos parceiros dos BRICS." (NIU, 2013, pp. 208-209) Além disso, a criação de ambos estabelece a concretude de uma demanda pela democratização da arquitetura financeira internacional e a reforma das instituições de Bretton Woods. (RODRIGUES, 2015)

Já a Organização para Cooperação de Xangai (OCX) é a organização política, econômica e militar mais eficiente para cooperação regional na Ásia Central, tendo desde 2001 a participação de China, Cazaquistão, Quirguistão, Rússia, Tadjiquistão e Uzbequistão (além de Irã e Mongólia como membros observadores), e, a partir de 2017, a adesão de Índia e Paquistão como membros plenos, abarcando cerca de metade da população mundial. Em termos militares, seus objetivos consistem no combate ao terrorismo, ao fundamentalismo religioso e ao separatismo na região da Ásia, preservando suas independências, soberanias, integridade territorial e estabilidade social. Logo, englobam acordos de cooperação e manobras militares, assim como cooperação econômica e cultural.

Além das ações bilaterais em parceria estratégica a partir dos anos 2000 (MAZAT; SERRANO, 2012), a aliança sino-russa vem se intensificando num pragmatismo em torno de interesses comuns (a despeito dos contenciosos históricos), principalmente em articulações multilaterais que buscam uma ordem mais multipolar na dimensão global, acirrando o Big Game na Eurásia. A partir desse 
contexto, a OCX propõe ser, explicitamente, um contrapeso aos EUA e à OTAN (FIORI, 2008), ou seja, "revela-se uma grande disputa entre Estados Unidos e seus aliados na OTAN, de um lado, e da OCX, ou China e Rússia e seus aliados, do outro, que deve ter impacto determinante no futuro geopolítico da região e global." (PADULA, 2018, p. 369)

Adicionalmente, ainda segundo Padula (2018), a Ásia Central é visualizada como espaço vital para a segurança energética e de suprimento de minerais estratégicos da China. Tal fato ocorre uma vez que existe o domínio estadunidense de passagens marítimas estratégicas, como o chokepoint do Estreito de Malaca, fundamental para o transporte energético marítimo na Ásia-Pacífico, fazendo com que os estrategistas chineses busquem rotas comerciais cada vez mais terrestres. É nesse contexto que surge o imperativo da construção de uma ampla e sofisticada rede de infraestrutura, de transportes e dutos pela Eurásia, lastreado, principalmente, pelo projeto geoeconômico do Belt and Road Initiative.

Conforme constatado, a China vem realizando uma atuação geopolítica crescente em distintos tabuleiros regionais, mas, concomitantemente, sua ênfase geoeconômica tem sido bastante incisiva, cuja atuação é exemplar, "através de investimentos, empréstimos, aquisição de empresas por parte de suas estatais, construção de infraestrutura e dutos." (PADULA, 2018, p. 367) Assim, define-se neste trabalho a geoeconomia como o uso de instrumentos econômicos para fins geopolíticos, tal qual pontuado por Blackwill e Harris (2016, p.20): "the use of economic instruments to promote and defend national interests, and to produce beneficial geopolitical results; and the effects of other nations' economic actions on a country's geopolitical goals." Nesta perspectiva, caso existam ganhos geopolíticos, o custo econômico é secundário, podendo até mesmo haver gastos maiores que lucros; a finalidade principal é o estabelecimento de áreas de influência.

Neste tocante, o maior conjunto de obras da história da humanidade foi proposto pelo presidente chinês Xi Jinping durante uma visita oficial à Ásia Central, em 2013, a denominada Nova Rota da Seda (NRS), também conhecida como Belt and Road Initiative (BRI), One Belt One Road (OBOR) e, mais recentemente, "World Landbridge". ${ }^{18}$ Este ressurgimento dos laços da China com o resto do continente

\footnotetext{
${ }^{18}$ Word Landbridge é uma visão ampliada do plano Eurasian Landbridge para o desenvolvimento econômico de todo o planeta. Este programa de desenvolvimento planetário seria a pedra angular de um novo sistema internacional de benefício comum entre as nações para cooperação mútua e progresso, um novo sistema que já está surgindo com os acordos históricos para uma nova ordem econômica internacional entre as nações dos BRICS e outras. O conceito vem sendo desenvolvido de
} 
euro-asiático, através da construção das chamadas "Rotas da Seda", é uma alusão ao termo cunhado em 1877 pelo geógrafo prussiano Ferdinand von Richthofen para descrever as rotas comerciais que conectavam a China ao oeste do Mediterrâneo durante as dinastias Han e Tang. (STUENKEL, 2018: FRANKOPAN, 2018) Ao buscar reestabelecer o corredor econômico que uniu Oriente e Ocidente no primeiro milênio da era cristã, a China intenta fortalecer os laços econômicos entre Ásia, África e Europa com investimentos de bilhões de dólares, que favoreceriam a conexão e o comércio entre os países, assim como confirmaria, direta ou indiretamente, a disputa pelo poder e hegemonia global.

O projeto foi anunciado com orçamento de quase US\$ 1 trilhão em investimentos em infraestrutura, principalmente na forma de empréstimos, para cerca de 1.000 projetos, num prazo de mais de trinta anos, com a primeira fase a ser concluída em 2021 (ano do centenário de criação do Partido Comunista Chinês) e o projeto como um todo realizado até 2049 (ano do centenário da Revolução Comunista Chinesa). A BRI visa possibilitar a propagação econômica ao criar um sistema interconectado de transporte, energia e infraestrutura digital, numa área de aproximadamente $70 \%$ da população global, cerca de $55 \%$ do PIB mundial e $75 \%$ das reservas de energia conhecidas, exigindo a colaboração entre quarenta governos localizados ao longo da rota da seda terrestre e marítima.

Em maio de 2017, a China reuniu cerca de trinta líderes nacionais em uma cúpula inaugural dedicada a apresentar o conceito de Cinturão e Rota. A realização do Fórum Belt and Road para a Cooperação Internacional foi apresentado como uma possibilidade real de alterar o jogo da economia global, um modelo de "globalização inclusiva" ou "globalização institucionalizada chinesa", "basada en la interconectividad, las inversiones en infraestructura y una superestructura institucional financiera controlada por los Estados" (VADELL; SECCHES; BURGER, 2019, p. 49), com um caráter estrutural de foco não liberal, uma contraposição a globalização neoliberal.

- Na descrição apresentada em Astana, Cazaquistão, a Belt and Road Initiative se delineia como um acordo comercial extremamente ambicioso, organizado em cinco dimensões: primeiramente, a coordenação de políticas (pela qual Xi Jinping vem realizando a tentativa de encontrar um denominador comum para diferentes políticas nacionais de desenvolvimento); a implementação de uma 
infraestrutura de transporte; a potencialização do comércio, com a remoção de barreiras; a integração monetária, desenvolvendo o renminbi como moeda global de comércio e investimento; e o incentivo às trocas e contatos mais intensos entre as pessoas. (MAÇÃES, 2018)

Em outros termos, o Belt and Road Initiative é um projeto, um espaço de ampliação do processo de acumulação chinês, de pragmatismo das tomadas de decisões políticas, de resiliência geopolítica e geoeconômica, e, concomitantemente, de carência de investimentos em infraestrutura nos países em desenvolvimento e ausência de instituições ocidentais em fornecê-los. Isto significa que a China buscará organizar e liderar uma parcela crescente das cadeias de suprimentos globais, reservando para si os segmentos de produção mais complexos e criando fortes vínculos de interdependência e colaboração com outros países. Como afirma Maçães (2018, p. 30), "the Belt and Road is the name for a global order infused with Chinese political principles and placing China at its heart". No âmbito mais geral, a construção da BRI faz parte da geoeconomia chinesa como agenda de desenvolvimento, de sustentação da sua expansão econômica e influência política regional e global.

d) Por uma nova arquitetura financeira mundial

O anseio de criação de uma nova arquitetura financeira internacional é um ponto fundamental no debate contemporâneo. A própria tentativa de mudança sistêmica passa por uma nova arquitetura financeira internacional, haja vista que moeda e finanças constituem relações de poder, e demonstram a assimetria entre países no sistema internacional. A alta dependência do dólar nas transações internacionais faz com que EUA tenham privilégios exorbitantes, cujos pressupostos paradigmáticos no sistema de dólar flutuante seriam: 1) alta capacidade de endividamento dos EUA (com relativa ausência de limites no déficit externo e público); 2) políticas neoliberais, baseadas na abertura da conta capital, alto volume de reservas depositadas no FED e baixo nível de gastos públicos; 3) compra de títulos da dívida pública estadunidenses por parte da China; 4) poder militar inquestionável e incomparável; e 5) ausência de alternativas monetárias ao dólar.

Entretanto, esses fatores vêm gradativamente se tornando mais vulneráveis no longo século XXI, principalmente em razão: 1) do crescente endividamento público e privado dos Estados Unidos; 2) da crescente estagnação econômica estadunidense; 3) da deterioração relativa de sua liderança militar; 4) da crise das 
políticas neoliberais (com a provável entrada num ciclo de Kondratiev recessivo); 5) da busca chinesa em diminuir a utilização do dólar no sistema de pagamentos com países parceiros; e 6) do surgimento de alternativas monetárias embrionárias ao dólar, como a internacionalização do renminbi (人民币) e o surgimento da moeda digital chinesa (E-RMB).

Esta disputa geoeconômica, ou geopolítica das finanças, se acentua após a crise econômica de 2008, em que a China visualiza uma oportunidade de avançar no seu projeto político-financeiro. Ainda que existam desafios para a internacionalização do renminbi ${ }^{19}$, distintos fatores apresentam uma tentativa de aumentar a confiança na moeda fiduciária chinesa no mundo, tais como: o aumento gradativo do comércio global chinês em renminbi, a internacionalização do seu sistema bancário chinês e dos Panda Bonds ${ }^{20}$, a intensificação de Investimentos Externos Diretos (IED) lastreados na moeda chinesa (inclusive no próprio Belt and Road Initiative), a criação de contratos futuros em Petroyuan ${ }^{21}$ na bolsa de Xangai; o estabelecimento de operações de Swaps $^{22}$ em renminbi, e o código SWIFT ${ }^{23}$ de pagamento em moeda nacional constituindo-se como o quinto no mundo. Este avanço (ou recuo) da sua estrutura financeira estabelecerá o ponto de inflexão numa nova arquitetura financeira internacional.

19 Dentre esses desafios, destacam-se: 1) dificuldade de se instituir como moeda de reserva financeira; 2) riqueza financeira global é calculada em dólar, e sua modificação é um passo qualitativo que esta moeda ainda não conseguiu realizar; 3 ) internacionalização exige abertura maior da conta financeira chinesa, e que, possivelmente, ocasionará disputas políticas internas na China; 4) paradoxalmente, baixa dívida pública é um problema para internacionalização, uma vez que passa pela oferta de títulos públicos globais que sirvam como âncora da riqueza financeira global; e 5) hierarquia e privilégio do sistema financeiro impõem limites para mudanças substanciais, sendo a questão da reserva de valor do dólar o ponto mais difícil de modificação.

20 Os Panda Bonds são títulos chineses lastreados em renminbi, cujas notas são vendidas por um emissor não chinês na China onshore. Os Panda Bonds são oferecidos aos tomadores de empréstimos internacionais como uma forma de atrair investidores domésticos, tornando-se, recentemente, amplamente internacionalizada.

21 Petroyuan é uma forma da moeda oficial chinesa destinada à negociação de petróleo, anunciada pelo governo chinês em setembro de 2017, e recebendo apoio de parceiros comerciais da China, como a Rússia, para que possa ser implantada como Petro-moeda. Em 26 de março de 2018, o governo chinês emitiu os primeiros contratos de comercialização de petróleo de longo prazo denominados em petroyuans. Este projeto existe para tentar competir com o petrodólar americano como principal moeda nas transações de petróleo bruto, cuja hegemonia lidera o mercado desde que o padrão dólar foi estabelecido em 1971, substituindo o padrão-ouro e ensejando aos EUA o poder de administrar o suprimento de moeda mundial.

22 Swap é uma operação de derivativos através da qual as partes realizam uma troca de rentabilidade de ativos financeiros predefinidos. Essa permuta de indexadores financeiros ocorre com o objetivo de reduzir riscos e de aumentar a previsibilidade para as partes do contrato.

${ }^{23}$ SWIFT é um sistema que tem como principal função permitir a troca de informações bancárias e transferências financeiras entre as instituições financeiras. 
No que se refere à criação da E-RMB, a digitalização das finanças é uma tendência e a inovadora tecnologia blockchain ${ }^{24}$ um imperativo para o futuro, principalmente num país onde mais de $90 \%$ das transações internas não são mais realizadas em papel-moeda. A criptomoeda é um sistema de transação cujas trocas são realizadas de forma transparente, podendo ser visualizado por todos através da tecnologia blockchain, que demonstra todas as transações no sistema de trocas. A inovação da moeda digital chinesa é que possuirá o controle da autoridade monetária chinesa, fazendo com que as transações não sejam compensadas pela comunidade num âmbito descentralizado. Dentro dessa tradição da inovação institucional chinesa, o experimento da moeda digital chinesa consiste numa nova e distinta tecnologia que poderá intensificar a utilização massiva de sistema de pagamentos na China, uma evolução natural do seu mercado de meios digitais de pagamento como o WeChat Pay e o Alipay. Ela vem sendo estudada desde 2015, intensificada em 2019, e lançada em 2020 como modelos-teste em quatro províncias chinesas: Shenzhen, Suzhou, Chengdu e Xiong'na.

Diferentemente das criptomoedas privadas, o Digital Currency Electronic Payment (DCEP) é apoiado pelo Estado chinês através do seu fundo de reserva, fazendo com o que seu valor nunca flutue especulativamente como as demais criptomoedas. Portanto, existe uma intermediação estatal politicamente centralizada, fazendo com que o controle das finanças e dos capitais seja colossal, facilitando a contabilidade e a velocidade das transações e pagamentos, além do lançamento pioneiro da tecnologia da economia de plataforma e controle da mudança tecnológica em seus próprios termos. Não é somente uma questão de tecnologia, mas também de política e soberania.

Geoestrategicamente, o E-RMB pode vir a constituir uma alternativa ao dólar no comércio internacional e, inclusive, driblar sanções financeiras internacionais, ao realizar transações num sistema de pagamentos alternativo que escape do sistema tradicional de pagamentos coordenado pelos EUA. Dessa forma, a China poderia intensificar suas relações comerciais e de investimentos com nações que sofrem restrições no comércio internacional, ampliando, inclusive, sua área de influência geopolítica a partir da disputa global no sistema de pagamentos high tech.

${ }^{24}$ O blockchain é uma rede que funciona com blocos encadeados seguros que carregam um conteúdo acoplado a uma impressão digital. No caso do E-RMB, esse conteúdo é uma transação financeira. 
É imprescindível visualizar que o controle, desenvolvimento e protagonismo da tecnologia blockchain é o ponto fundamental no processo de criação da E-RMB. Principalmente no que se refere à promoção do compartilhamento de dados, a otimização de processos de negócios, a redução de custos operacionais, a melhoria da eficiência de sinergia e a construção de um sistema confiável, que realize o rastreamento em tempo real e possibilite o controle de fluxos financeiros ilícitos, como lavagem de dinheiro e evasão fiscal. Além disso, é altamente relevante do ponto de vista estratégico na corrida e guerra tecnológica em curso, constituindo-se como o início de um processo que não irá modificar a dependência do dólar no curto prazo, mas é um passo para a independência monetária e alternativa funcional a este sistema de liquidação no longo prazo.

\section{e) Nova Política Externa}

Nas duas primeiras décadas do século XXI, a política externa da China caracterizou-se por um processo de projeção internacional baseado no paradigma do desenvolvimento pacífico e harmonioso, sustentado na cooperação Sul-Sul. (MILANI, 2012) Como parte deste processo, o país aproximou-se de regiões como a América Latina e África, ocupando espaços geopolíticos e geoeconômicos que resultaram em crescimento dos vínculos comerciais, elevação dos investimentos/financiamentos e a concretização de acordos bilaterais e multilaterais. Em outros termos, "a China saiu de uma condição periférica para o centro do sistema econômico global, o que alterou geograficamente o centro do processo de acumulação capitalista global." (VADELL; RAMOS; NEVES, 2016, p. 67) Em grande medida, tal fato se deve a assertividade crescente de sua política externa, principalmente após a entrada de Xi Jinping ao poder, em 2013, ensejando a possibilidade de um "Fator Xi" na China atualmente.

Indubitavelmente, $\mathrm{Xi}$ Jinping é uma das figuras mais importantes da história chinesa. Em 2018, ele recebeu uma honraria até então destinada apenas a Mao Zedong: suas ideias foram incluídas nas constituições do Partido Comunista Chinês (PCCh) e do Estado chinês, sob o nome "Socialismo com Características Chinesas para uma Nova Era." (中国特色社会主义). Neste tocante, segundo Lima (2018), a China contemporânea possui quatro pilares em matéria de política externa: 1) manutenção de sua integridade territorial; 2) reconhecimento pela comunidade 
internacional da política de "uma só China"; 3) propiciar o desenvolvimento econômico do país; 4) incrementar seu prestígio no âmbito internacional.

Um dos termos mais utilizados consiste no denominado "sonho chinês" (中国梦). O conceito está intimamente ligado à figura de Xi Jinping, tendo sido generalizado na política externa do país, em anúncios oficiais e na própria personificação da ideologia política do líder chinês. Ele consiste na descrição de um conjunto de ideias para os indivíduos, a coletividade e o próprio Estado chinês, com o objetivo de alcançar a revitalização e prosperidade nacionais, e, a partir disso, construir metas que, quando atingidas, simbolizariam a efetivação desse sonho. Segundo Xi Jinping, o "sonho chinês" possibilitaria aos cidadãos chineses ousar sonhar, trabalhar assiduamente para realizar os sonhos e contribuir para a revitalização da nação. (CHINA, 2013) Além disso, promete garantir a construção de uma sociedade moderadamente próspera e transformar a China num país socialista moderno, forte, democrático, culturalmente avançado e harmonioso. (XINHUA, 2019)

Outro ponto fundamental para a compreensão da política chinesa num horizonte de longo prazo, e que possui relação direta com o denominado sonho chinês, consiste da chamada two centenary goals (两个一百年). Objetivando retomar sua grande civilização, a China buscará cumprir duas metas: 1) acabar com a pobreza absoluta até 2021 (ano do centenário do Partido Comunista); e 2) ser um grande centro irradiador de poder no sistema internacional em 2049 (ano de centenário da fundação do Estado chinês). Jin (2016) afirma que the two strategic one hundred goals visa transformar a China numa potência até 2049, trazendo centenas de milhões de pessoas da linha da pobreza para a classe média, desenvolvendo intensamente sua infraestrutura, complexificando tecnologicamente sua indústria e construindo sua presença diplomática e militar no exterior.

De modo complementar no curto prazo, Yan (2014) visualiza uma política externa na era Xi com transformações substanciais e crescentemente assertivas, caracterizada pelo que o autor denomina de estratégia do "striving for achievement" (奋发有为). Ele argumenta que a política externa chinesa precisou se adaptar e abandonar um perfil mais comedido para adotar uma postura mais afirmativa no cenário internacional. Adicionalmente, afirma que a ascensão de Xi Jinping ao poder não foi o início da transição da política externa da China de um modelo low profile para um high profile, mas forneceu a necessária legitimação da transição. 
These tensions intensified China's domestic debate over the necessity of adhering to the taoguangyanghui (keeping a low profile, KLP hereafter) foreign policy strategy adopted by Deng Xiaoping during 1990-1991. This debate has lasted for years before Chinese President Xi Jinping delivered a speech at the foreign affairs conference of the Chinese Communist Party (CCP) on October 24 2013. In this speech, Xi formally presented the strategy of fenfayouwei (striving for achievement, SFA hereafter), signaling a transformation of China's foreign strategy from the KLP to the SFA. (YAN, 2014, pp. 153-154)

O "Fator Xi" é uma visão estratégica multidimensional, multilateral e multiorganizacional que visa aumentar a credibilidade estratégica e o rejuvenescimento nacional da China, assim como estabelecer uma "comunidade de futuro compartilhado para a humanidade" (人類命運共同體). Entretanto, na medida em que se eleva a assertividade dessa política externa chinesa, os conflitos com o centro hegemônico tendem a se acirrar, conforme visualizado com a guerra comercial, tecnológica e ideológica no final da década de 2010. A própria pandemia do coronavírus é um ponto de inflexão nítido dessa nova diplomacia chinesa, inclusive com a ativa cooperação internacional e provimento de bens públicos globais. Esse "novo normal chinês" tende a pautar a agenda do debate global, diminuindo a atual interdependência sino-americana e, consequentemente, elevando a sua competição e intensificando a contradição estrutural entre uma potência ascendente e uma hegemonia do status quo.

\section{Considerações finais}

A partir do conceito chinês de Tiānxià (天下), de priorização da harmonia e do desenvolvimento compartilhado mundial, o presente artigo buscou apresentar breves reflexões relacionadas à hipótese de transição hegemônica no século XXI. Utilizando-se de prerrogativas empíricas da China contemporânea, tais como uma nova formação econômico-social, evolução das capacidades científico-tecnológicas, formação de blocos geopolíticos e geoeconômicos, concepção de uma nova arquitetura financeira internacional e nova política externa assertiva, visualiza-se que o Zhōngguó (中国) vem exercendo uma posição fortemente anti-imperialista, formando um Sul global claramente contra-hegemônico.

Após a exposição dos pontos principais deste trabalho, evidencia-se que o próprio conceito de "capitalismo de Estado", tão em voga nas interpretações acerca da China, não possui sentido científico nem histórico. Desde o Tratado de Vestfália, em 1648, tanto capitalismo quanto Estado se complementam reciprocamente; não 
existe capitalismo sem Estado, mas o Estado pode existir para além do capitalismo. A experiência embrionária e original dessa nova formação econômico-social centraliza os interesses de mercado a partir de um projeto de longo prazo alheio à especulação financeirizada, delineado por um Partido e uma sociedade que, em sua essência, são harmoniosamente confucianos, filosoficamente taoístas e comunitariamente maoístas. Não compreender essa especificidade é um equívoco que serve para equiparar as contradições desse processo de transformação de longa duração com o modus operandi do status quo dos países ocidentais.

Nesta transição hegemônica sui generis, a China se apresenta como a alternativa concreta ao neoliberalismo financeirizado e à globalização neoliberal, que coloca a centralidade do estágio primário do socialismo chinês e do Estado desenvolvimentista e anti-imperialista civilizacional numa alta capacidade de entregar os resultados previamente estabelecidos e relacionados ao desempenho politico. Adicionalmente, a experiência chinesa vem exacerbando a essência do capitalismo como uma relação contraditória e paradoxal de crise e expansão, de dominação que restringe a autodeterminação dos países e povos, que se pauta nas liberdades individuais em detrimento das liberdades coletivas.

A pandemia foi reveladora das contradições desse modelo ocidental, com deficiências estruturais e de capacidades estatais no fornecimento de bens públicos e apaziguamento de externalidades econômicas negativas. A China sai fortalecida ao apresentar eficiência no controle pandêmico, na cooperação internacional e na retomada econômica. Paralelamente, a disputa hegemônica, intensificada pela pandemia da Covid-19, não pode ser comparada a uma "Nova Guerra Fria" entre EUA e China, uma vez que os chineses não buscam impor seu modelo, não exportam seu sistema econômico-ideológico. Pelo contrário, se inserem de modo distinto na própria lógica do sistema de mercado global, "vencendo" nas próprias regras estabelecidas pela ordem mundial pós-Segunda Guerra.

Neste sentido, a transição hegemônica caminha paralelamente ao desengajamento dos EUA no sistema internacional, reforçando a globalização ao estilo chinês, cada vez mais diversificada e complexa, de respeito às diferenças e diversidades dos sistemas políticos e culturais de cada país, diferentemente do modelo neoliberal que advoga a uniformização de valores, ideias e do sistema político-econômico. Além disso, uma vez que a mudança sistêmica não é imediata nem unidirecional, ela somente é factível e exequível na longa duração, 
apresentando-se como multifacetada, conforme o presente artigo buscou demonstrar.

Em suma, este trabalho não buscou apresentar um fatalismo premeditado baseado na futurologia acadêmica. Foi pleiteado que a crise estadunidense é um processo de longa duração e que pode, inclusive, ser revertido, haja vista a resiliência e superioridade dos Estados Unidos em diversos setores tecnológicos, na moeda de reserva internacional e no incomparável pode militar. Entretanto, o método empírico-dedutivo auxilia na conformação de que, a partir da materialidade histórica, existem fortes sinais indicativos de que esteja ocorrendo uma transição hegemônica no sistema mundial no longo século XXI.

\section{REFERÊNCIAS}

ARRIGHI, Giovanni. Adam Smith em Pequim: origens e fundamentos do século XXI. São Paulo: Boitempo, 2008.

ARRIGHI, Giovanni. O longo século XX: dinheiro, poder e as origens de nosso tempo. Rio de Janeiro: Contraponto, 1996.

BLACKWILL, Robert D.; HARRIS, Jennifer M.. War by other means: geoeconomics and statecraft. Cambridge, Massachusetts: The Belknap Press Of Harvard University Press, 2016.

CHINA. State Council. . Made in China 2025: 《中国制造2025》. 2015.

CHINA. Youth urged to contribute to realization of 'Chinese dream'. 2013. Disponível em: http://www.china.org.cn/china/2013-05/05/content_28731285.htm. Acesso em: 5 maio 2013.

ECONOMY, Elizabeth C.; LEVI, Michael. By all means necessary: How China's resource quest is changing the world. New York: Oxford University Press, 2014.

ENCINA, Cladia Labarca. El capitalismo confuciano en La era de La globalización: nuevas bases para construir xinyong y guanxi - lecciones para Chile. Estudios Internacionales (163), pp.23-46, 2009.

FIORI, José Luís da Costa. O poder global e a nova geopolítica das nações. São Paulo: Boitempo Editorial, 2007.

FIORI, José Luis. O sistema interestatal capitalista no início do século XXI. In: FIORI, J.L.; MEDEIROS, C.A. \& SERRANO, F. O Mito do Colapso do Poder Americano. Rio de Janeiro: Record, 2008.

FRANKOPAN, Peter. The new silk roads: the present and the future of the world. London: Bloomsbury Publishing, 2018.

GABRIELE, Alberto. Enterprises, Industry and Innovation in the People's Republic of China: questioning socialism from deng to the trade and tech war. London: Springer, 2020. 
GONG, Maoguo; WANG, Shanfeng; LIU, Wenfeng; YAN, Jianan; JIAO, Licheng. Evolutionary computation in China: a literature survey. Caai Transactions On Intelligence Technology, [S.L.], v. 1, n. 4, p. 334-354, out. 2016.

JABBOUR, Elias. China, socialismo e desenvolvimento - sete décadas depois. São Paulo: Anita Garibaldi; Fundação Maurício Grabois, 2019.

JABBOUR, Elias; DANTAS, Alexis. "The political economy of reforms and the present Chinese Transition". Brazilian Journal of Political Economy, v. 37, n. 4, p. 789-807, 2017.

JABBOUR, Elias; PAULA, Luis Fernando de. "A China e a "socialização do investimento": uma abordagem Keynes-Gerschenkron-Rangel-Hirschman". Revista de Economia Contemporânea. N. 22, v. 1, p. 1-23, 2018.

JIN, Xu. Debates in IR Academia and China's Policy Adjustments. The Chinese Journal of International Politics, v.9, n.4, p.459-489, 2016.

KAVALSKI, Emilian (Ed.). The Ashgate Research Companion to Chinese Foreign Policy. Surrey: Ashgate Publishing, 2012.

KISSINGER, Henry. Sobre a China. Rio de Janeiro: Objetiva, 2011.

KONDRATIEV, Nicolai. Los ciclos largos de la coyuntura economica. México D.F.: Unam, 1992.

LEONARD, Mark. What does China think? London: Fourth Estate, 2008.

LIMA, Marcos Costa. A nova teoria das relações internacionais chinesa e a ascensão do país: o conceito de Tianxia. In: VADELL, Javier (Org.). A expansão econômica e geopolítica da China no século XXI. Belo Horizonte: Editora Puc Minas, 2018. Cap. 1. pp. 13-42.

LIN, Zhou. O 5G abre as portas para o futuro. China Hoje, São Paulo, ano 5, n. 30, p. 1820, Abr/Mai 2020.

MAÇÃES, Bruno. Belt and Road: a chineses world order. London: Hurst, 2018.

MAJEROWICZ, Esther; MEDEIROS, Carlos Aguiar de. Chinese industrial policy in the geopolitics of the information age: the case of semiconductors. Revista de Economia Contemporânea, [S.L.], v. 22, n. 1, p. 1-28, 11 jun. 2018. FapUNIFESP (SciELO).

MARTINS, Carlos Eduardo. Globalização, dependência e neoliberalismo na América Latina. São Paulo : Boitempo, 2011.

MAZAT, Numa; SERRANO, Franklin. A geopolítica das relações entre a Federação Russa e os EUA: da .:cooperação:: ao conflito. Oikos, Rio de Janeiro, v. 11, n. 1, p. 5-35, 2012.

MILANI, Carlos. Aprendendo com a história: críticas à experiência da Cooperação Norte-Sul e atuais desafios à cooperação Sul-Sul. Caderno CRH, vol.25, n.65, pp.211-231, 2012.

NAPOLEONI, Loretta. Maonomics: por que os comunistas chineses se saem melhores capitalistas do que nós. Rio de Janeiro: Bertrand Brasil, 2014.

NAUGHTON, Barry. Is China Socialist? Journal Of Economic Perspectives, Nashville, v. 31, n. 1, p.3-24, 2017.

NIU, Haibin. A Grande Estratégia Chinesa e os BRICS. Contexto Internacional, Rio de Janeiro, v. 35, n. 1, p.197-229, jan./jun. 2013.

NOGUEIRA, Isabela; GUIMARÃES, João Victor: BRAGA, João Pedro. "Inequalities and capital accumulation in China". Brazilian Journal of Political Economy, v. 39, n. 3, p. 449469, 2017. 
PADULA, Raphael. A geopolítica estadunidense e a Eurásia. In: FIORI, José Luis (org.). Sobre a guerra. Petrópolis: Vozes, 2018. p. 340-370.

PIKETTY, Thomas; YANG, Li; ZUCMAN, Gabriel. "Capital accumulation, private property and rising inequality in China". NBER Working Paper, n. 23368, Apr. 2017.

RAMO, Joshua Cooper. The Beijing Consensus: notes on the new physics of chinese Power. London: Foreign Affairs Policy Centre, 2004.

RODRIGUES, Bernardo Salgado. La nueva arquitectura financiera mundial: Perspectivas del Banco de los BRICS y del Banco del Sur. In: TAVILLA, Pablo; ROBBA, Alejandro (Ed.). Congreso de Economía Política Internacional año 2014. Unm Editora, 2015. p. 7992.

RODRIGUES, Bernardo Salgado. Geopolítica, desenvolvimento e integração na América do Sul?: os projetos de poder estadunidense e chinês na amazônia sul-americana (2001-2016). 2020. 392 f. Tese (Doutorado) - Curso de Economia Política Internacional, Universidade Federal do Rio de Janeiro, Rio de Janeiro, 2020.

RODRIGUES, Bernardo Salgado. La nueva arquitectura financiera mundial: Perspectivas del Banco de los BRICS y del Banco del Sur. In: TAVILLA, Pablo; ROBBA, Alejandro (Ed.). Congreso de Economía Política Internacional año 2014. Unm Editora, 2015. p. 7992.

SCHWAB, Klaus. A quarta revolução industrial. São Paulo: Edipro, 2016.

SHAMBAUGH, David. China goes global: the partial power. New York: Oxford University Press, 2013.

SISCI, Francesco. A brave new China: the big chance. Firenze: Goware, 2014.

STUENKEL, Oliver. BRICS: e o futuro da ordem global. Rio de Janeiro/são Paulo: Paz e Terra, 2017.

STUENKEL, Oliver. O mundo pós-ocidental: potências emergentes e a nova ordem global. Rio de Janeiro: Zahar, 2018.

VADELL, Javier. La iniciativa BRICS y China: entre la emergencia y la irrelevancia. Nova Economia, [S.L.], v. 29, n. 2, p. 401-428, ago. 2019. FapUNIFESP (SciELO).

VADELL, Javier. Rumo ao século chinês? A relação Estados Unidos-China pós 11/09. Carta Internacional, Belo Horizonte, v. 6, n. 2, p.97-111, jul./dez. 2011.

VADELL, Javier; RAMOS, Leonardo; NEVES, Pedro. As implicações internacionais do modelo chinês de desenvolvimento do Sul Global: Consenso Asiático como network power. In: LIMA, Marcos Costa (Org.). Perspectivas Asiáticas. Rio de Janeiro: Folio Digital, 2016. p. 67-90.

VADELL, Javier; SECCHES, Daniela; BURGER, Mariana. De la globalización a la interconectividad: reconfiguración espacial en la iniciativa belt \& road e implicaciones para el sur global. Revista Transporte y Territorio, [S.L.], n. 21, p. 44-68, 1 out. 2019. Editorial de la Facultad de Filosofia y Letras - Universidad de Buenos Aires.

WALLERSTEIN, Immanuel. El moderno sistema mundial II: el mercantilismo y la consolidación de la economía-mundo europea 1600-1750. Madri: Siglo XXI, 1984.

WALLERSTEIN, Immanuel. The modern world system II: Mercantilism and the Consolidation of the European World-Economy, 1600-1750. Bingley: Emerald, 1980.

WHITLER, Kimberly A. What Western Marketers Can Learn from China. Harvard Business Review, 2019. 
XIN, Zhang. Desenvolvimento da IA renova a economia global. China Hoje, São Paulo, v. 5, n. 30, p. 29-31, Abr/Mai 2020.

XINHUA (China). Xi emphasizes "struggles" to achieve national rejuvenation. Xinhua Net. Beijing, 3 set. 2019.

YAN, Xuetong. From Keeping a Low Profile to Striving for Achievement. The Chinese Journal Of International Politics: Pequim, 2014. p. 153-184.

\section{NOTAS DE AUTOR}

\section{CONTRIBUIÇÃO DE AUTORIA}

Bernardo Salgado Rodrigues - Concepção. Coleta de dados, Análise de dados, Elaboração do manuscrito, revisão e aprovação da versão final do trabalho

Carlos Eduardo da Rosa Martins - Concepção e elaboração do manuscrito. Coleta de dados Participação ativa da discussão dos resultados; Revisão e aprovação da versão final do trabalho.

\section{FINANCIAMENTO}

Não se aplica.

CONSENTIMENTO DE USO DE IMAGEM

Não se aplica

\section{APROVAÇÃO DE COMITÊ DE ÉTICA EM PESQUISA}

Não se aplica.

\section{CONFLITO DE INTERESSES}

Não há conflitos de interesse

\section{LICENÇA DE USO}

Este artigo está licenciado sob a Licença Creative Commons CC-BY. Com essa licença você pode compartilhar, adaptar, criar para qualquer fim, desde que atribua a autoria da obra.

\section{HISTÓRICO}

Recebido em: 13-09-2020

Aprovado em: 22-10-2020 